\title{
Chinese Scholars' Perspective on John Updike's "Rabbit Tetralogy"1
}

\author{
Zhao Cheng
}

Foreign Languages Studies School, Soochow University, China

Received October 15, 2019; Revised November 25, 2019; Accepted December 4, 2019

Copyright $\bigcirc 2020$ by authors, all rights reserved. Authors agree that this article remains permanently open access under the terms of the Creative Commons Attribution License 4.0 International License

\begin{abstract}
Updike's masterpiece, using skillful realism, succeeded in drawing a panoramic picture of the American society from the 1950s to the early 1990s in the "Rabbit Tetralogy." Updike strives to reflect the changes in contemporary American social culture for nearly half a century from the "rabbit" Harry, the everyman of the American society and the life experiences of his ordinary family. "Rabbit Tetralogy" truly reflects the living conditions of the contradictions of contemporary Americans: endless pursuit of free life or independent self and the embarrassment and helplessness of it; the customary life and hedonism under the traditional values, the intense collision of self-indulgent lifestyles inspired by thought. The endless pursuit of so-called freedom and self is bred. As the greatest masterpiece, John Updike's "Rabbit Tetralogy" shows readers nearly half a century of the American's social life, and provides literary critics listless raw material as well, and becomes a beloved apple in the mind's eye of Chinese scholars. This paper, adopting a comparative method, combs the historical clue of the study in the past three decades, two different phases and the respective research results and the main viewpoints are summarized and presented. Also this paper probes into the main problems in this field, i.e. the lack of sufficient research perspectives, relative research redundancy and the lack of communication between home and abroad, etc. and engages to point out the direction and tendency of future research. Further studies are suggested to conduct via literary space theory, etc. to enhance the study of "Rabbit Tetralogy".
\end{abstract}

Keywords John Updike, "Rabbit Tetralogy", Current Situation, Review, Future Study

\section{Introduction}

John Updike (1932-2009) was one of the most important, most productive, and most awarded writers in the United States in the second half of the twentieth century. "Rabbit Tetralogy", Updike's masterpiece, the core of the entire literary creation system of Updike, composed of "Rabbit Run" (1960), "Rabbit Redux" (1971), "Rabbit is Rich" (1981), and "Rabbit at Rest" (1991), represents the highest achievement of the writer's novel creation. In contemporary American literature, the publication of Rabbit Tetralogy is considered as a landmark event, and Updike's character "Rabbit" Harry, one of the "most confusing literary figures in traditional American literature", has become a classic figure in contemporary American literature.

"Rabbit Tetralogy" closely touches the pulse of the times, in which historical events are closely related to the details of daily life. Great changes in American society and culture from the 1950s to the early 1990s are depicted in "Rabbit Tetralogy", involving some important historical backgrounds of contemporary America such as the Vietnam War, the moon-landing, the energy crisis, and the ending of the Cold War, thus forming a life picture of contemporary American society. One of the main lines throughout "Rabbit Tetralogy" is the endless pursuit of individual freedom and self by the hero, the Rabbit, as well as the setbacks and failures encountered therein. The reader can see the Rabbit's honesty in "Rabbit Tetralogy", his pragmatism, his guilt, his arrogance, his racism, narrow national outlook/narrow nationalism, and selfishness.

\section{Materials and Methods}

Domestic research on Rabbit Tetralogy began with two articles written by HUANG Jiade (黄嘉德) in 1979 and 1981: "On Updike's "Rabbit, Run" and "Ten Years of Vicissitude: Comment on John Updike The novel "Rabbit Redux". HUANG Jiade's introduction to Rabbit Tetralogy is regarded by the academic circles as Rabbit Tetralogy and even the first attempt of Updike's Chinese study which 
exerts important historical significance. Research history can be divided into two stages. In the 1980s, the study in the first stage was based on translation. GUO Yingjian (郭 英剑） translated "Rabbit, Run" and published in the "World Literature" magazine, Nos. 5 and 6 of 1986, and opened the translation of "Rabbit Tetralogy". In 1987, Chongqing Publishing House first published the translation of "Rabbit, Run". In 1998, Henan People's Publishing House launched the first "Rabbit Tetralogy" in China for the first time. In December 2007, Shanghai Translation Publishing House organized the translation and publication of Rabbit Tetralogy, entitled "Rabbit, Run," "Rabbit Redux," "Rabbit is Rich," and "Rabbit at Rest," in early 2008. The National Symposium on "Rabbit Tetralogy" was held in Shanghai, marking the beginning of a new phase in the study of Rabbit Tetralogy series in China. (ZHAO Cheng, 2015: 65)

In the 1980s, most Chinese scholars adopted class analysis method to introduce the realism structure and performance in Rabbit Tetralogy in the research perspectives, focuses, research methods and research results. The technique is to discuss the deep reason why the rabbit runs away from home and thinks that the rabbit's mediocrity reflects the vulgarity of contemporary American society. To sum up, the following characteristics are presented: First, most scholars stand on the moral high ground and think that Updike explores topics such as humanity and religion in the moral debate of Rabbit Tetralogy Updike believes that rabbits through self-identification and escape attempt to achieve self-identification and personal freedom, and the realization of the middle class life pattern, but ultimately end in failure, which was accepted by scholars of this historical period; Second, most of the reviewers aim to explore the underlying causes of rabbit escaping, that is to say, his extreme dissatisfaction with reality, the belief and needs reflected in the ultimate problem, the contradictory "contradictory tendency" and the moral dilemma. Again, most of the comments used the popular analysis method of the garbage at that time, and analyzed the class situation reflected in the rabbit as a member of the working class and the situation of the black people's rights movement in the 1960s. Finally, scholars of this period in-depth examination of Updike's literary identity have always recognized that Updike is a person like "everyone with strong modernism and realism expressions and feelings." (SHENG Ning 1984: 94)

Since the 1990s, with the Westernization of Western literary criticism theory, domestic scholars have learned the essence of these new literary criticism theories and tried to apply them to the study of literary text criticism. The 3rd issue of Foreign Literature Review in 1993 contains WANG Shouren (王守仁) 's academic paper "The Puzzle of a Loser--On Updike's 'Rabbit at Rest"', which is the domestic Updike study, especially Rabbit Tetralogy. The study of series of novels has epoch-making results. Its publication opened the prelude to the study of Updike and its "Rabbit Tetralogy" by the domestic academic system. In this kind of environment, the research on the domestic "Rabbit Tetralogy" series of novels has entered a new era. Experts and scholars have borrowed different literary criticism theories and cut into the "Rabbit Tetralogy" study from different research perspectives. A series of new academic findings, summed up, have reached consensus on the following aspects:

First of all, similar to Western academic circles, domestic scholars pay attention to the study of religious and philosophical thoughts in the "Rabbit Tetralogy." JIN Hengshan（金衡山）believes that religion is a recurring theme in Updike's novels. The concept of religion is deeply influenced by Karl Barth, one of the main theologians of the 20th century. His access to Barthism and contemporary American culture is closely related (JIN Hengshan, 2007: 103-111) GUO Yingiian who pointed out that religious themes appear without exception in Updike's novels, short stories, poems, literary criticism and other four types of works (GUO Yingjian, 2000); HONG Zengliu (洪增流) believes that the embarrassing situations of modern Americans in the faith and the author's contradictory mentality on religious issues are vividly displayed in the book "Rabbit, Run". The relationship between religion and secularism is increasingly evident in contemporary American society. With the influence of the traditional religions such as the Puritanism on the influence of the public, the religious secularization began to form and became increasingly manifested. The concrete manifestation was that the sacred religion gradually merged with the secular life to lead to the formation of secularized religion. (HONG Zengliu, 2004: 111-116) HAO Yunzhi (郝蕴志) in the doctoral thesis "John Updike and the Christian Faith", combed the specific representation of religious themes in Updike's works, subdividing into beliefs, Christian Protestantism, churches, believers, pastors, emerging religions, etc. Religion reflects Updike's view that faith is essential to the survival and redemption of Americans. However, the secularized religions and clergy have become increasingly unstoppable and unable to guide the people to maintain this belief. New forms of religion cannot make people get this faith. Although Updike thought hard, he could not find a solution, and thus revealed a confusing attitude towards life. (HAO Yunzhi, 2007);

Secondly, it comments on the imagery in the novel: from the perspective of feminism, through the shaping of female characters closely related to Harry, which aims to reveal the female consciousness of Updike and its source (DONG Wensheng 1998: 52-56);

Again, the character analysis of the protagonist Harry: the researcher analyzes his vacillating personality and its causes by showing the character of the rabbit; first, the contradiction between the past and the present; secondly, the duality of his role; again, the external environment and 
the inner heart. Demystifying the conflict; and by highlighting the vertical structure of the novel (from the noble to the humble movement) and the horizontal structure (fleeing - returning - then fleeing - then returning) highlighting the rabbit's desire to escape responsibility but subjecting to double constraints. And then representing the living conditions of people in that era. In addition, the reviewers also explored the deep reasons why the protagonist Harry escaped from reality, family, and responsibility from the aspects of death, sex, and religion. (DONG Wensheng, 1996);

Fourth, the cultural interpretation of the novel: At the end of the 20th century, with the introduction of cultural theory, the comments on Updike's novels began to take a cultural perspective. The rabbit has also become "the United States of the era of him (referring to the rabbit, the author's note)." The dilemma facing the rabbit also reflects the social and cultural dilemma. (JIN Hengshan, 2005: 68-76); GUO Yingjian pays attention to the shaping of female images in Updike's "female novels", traces the historical evolution of women's status, and explores the shaping of these female images to arouse feminists and female readers. The various reasons for the violent sniper confirm that Updike is a thinker who deeply explores the predicament and historical destiny of contemporary women. The thinker truly reflects reality and rationally thinks about the true predicament of women in contemporary society (GUO Yingiian, 2018: 173-184).

Fifth, looking at the changes in American society from the works: outlining the highly materialized consumerist lifestyle of the middle class and the resulting lack of moral beliefs. (GUO Jide, 1992: LUO Changbin, QIAN Mansu, 1997: 34-38; JIN Hengshan, 2008: 33-36).

\section{Results}

Domestic research presents two transformations: First, the innovation and enrichment of research methods: abandoning the traditional method of class analysis and criticism in the past due to historical limitations and ideology, citing the new Western literary criticism theory, transforming to text analysis, and carrying out the works of writers Research; Second, the study of breadth and depth of change: the realization of the point-to-face transition. It is no longer limited to the chronological form of the background of the times, the life of the writer and the meaning of the works. The research results include religious philosophy, consumer culture, post-colonial theory, Dadaism, and ecofeminism.

At present, the research on the series of "Rabbit Tetralogy" series in China still has the following shortcomings:

First, the depth of research needs to be further deepened, and the scope of research needs to be further broadened. According to the author's search in China Knowledge
Network, as of August 2019, there is no doctoral dissertation about Rabbit Tetralogy (only one doctoral dissertation of HAO Yunzhi, Nankai University, "John Updike and Christianity)). There are only 11 master's thesis, involving the use of feminist, literary Darwinism and existentialist analytical works. Searching the catalogue of 38 years of the four authoritative journals of foreign literature since $1980-2019$, there are only 16 papers on Updike, only 3 of which focus on Rabbit Tetralogy, which are related to the political novel perspective of "Rabbit Tetralogy" (WANG Yuexi 1998: 74); the secularized religious theme in Rabbit Tetralogy and the innovation of American social fashion novels (XU Ming 2012: 152-158). A considerable part of the article is based on "Rabbit, Run", which is not enough to provide complete clues. The research results have diachronic defects. For the "Rabbit Is Rich" and "Rabbit at Rest", they won the Pulitzer Prize. At present, there are only two academic papers in domestic research, namely WANG Shouren's "The Puzzle of a Loser: On Updike's 'Rabbit at Rest' (WANG Shouren, 1993: 79-84) and HAO Yunzhi's "Rabbit is Rich" With the materialized world of the American middle class (HAO Yunzhi, 2011: 61-64). Due to national conditions and other reasons, there is no domestic analysis of the neutral theme of Updike's works. At the same time, environmental problems brought about by social progress and economic development are rarely seen in domestic research;

Second, the results of articles using postmodern literary criticism theory have emerged, but they have not formed a mainstream. In 1993, WANG Shouren published a paper "The Perplexity of a Loser--On Updike's 'Rabbit at Rest" for the first time, completely showing the typical characters of "rabbit" to Chinese readers and applying post-modern literary theory. It's said that the novel hero "rabbit" is an "anti-hero" character. A large number of research articles focus on social and cultural themes and character analysis, and there are simple repetitions. But there is lack of in-depth and detailed thematic research in the study of social and cultural themes;

Third, dialogue and exchange activities between academic circles at home and abroad are relatively in shortage. In addition to the 2008 National Seminar on "Rabbit Tetralogy" held by Shanghai Translation Publishing House in 2008, there are no other exchanges and academic activities for the study of Rabbit Tetralogy. At present, there is no foreign literature research institution to conduct dialogues or other academic exchanges with foreign counterparts, especially the US Updike Society. These achievements are inconsistent with Updike's academic identity, and it is difficult to distinguish it from China's cultural identity. (ZHAO Cheng, 2015: 66-68)

At present, there is no research on the use of spatial criticism theory in the domestic academic circles for Rabbit Tetralogy. All of this shows that Rabbit Tetralogy has a huge research space. 


\section{Discussion - A Heterogeneity Perspective}

The 20th century has witnessed the upspring of endless literary theory, and the social life of the United States in the past half a century exhibited by the "Rabbit Tetralogy" provides literary critics with numerous corporeal material. In the Post-modern context, it is very necessary to apply the new literary criticism theory to analyze this work. At present, the researches on Rabbit Tetralogy borrowed from the theory of space at home and abroad are relatively rare. Post-colonialism, feminism, ecocriticism and space theory can all find their own use in this series of novels. This also provides a larger research space for the previous articles.

Updike, in his "Rabbit Tetralogy", has shaped a series of literary spaces in various forms, revealing the "cultural contradictions" of contemporary American society, manifesting the evolution of the traditional values of American society, disclosing the living conditions of ordinary Americans infested by contradictions in contemporary society. Space has multiple spatial dimensions and profound ideological connotations in the Rabbit Tetralogy series of novels. Updike's "Rabbit Tetralogy" provides a powerful example for the application of space theory in the field of literary studies, and opens up new insight for literary text research. This dissertation, based on the related research results of "Rabbit Tetralogy" at home and abroad, drawing upon Foucault's heterogeneous space theory, is aimed to comb the representation and origin of spatial heterogeneity of different kinds of literary spaces constructed in Updike's novels, from the interdisciplinary perspectives, i.e. the sociological theories. Beauvoir's feminist criticism, Maslow's hierarchy of needs, Sigmund Freud's and Jacques Lacan's psychoanalysis theory, and Cornell's masculinity crisis theory shed light on the study of the heterogeneity of each specific literary space and contribute, to a large extent, to the reappearance/ restoration of multi-channel, abstract space mapping, including the objective existence of many social phenomena such as the women's liberation movement, counter-cultural movement, social bondage of gender mechanism, domestic political, economic and cultural changes, as well as the interaction between individual psychological space writing and self-construction of characters in the novel, thus fully demonstrating the deep and overall reflection on gender space, psychological space, social space and cultural space.

Future study can be conducted in the following framework. First is to clarify the origin of the research, review the history and current situation of the study of Updike's novels at home and abroad, comb the historical development of the research of contemporary spatial criticism theory, introduce the theoretical framework of this dissertation - Michel Foucault's heterogeneous space theory, and put forward the research purpose, significance and method of this dissertation. The main body adopts
Henri Lefebvre's "space production" theory of ternary dialectic, that is, the "lived" of space, the "conceived" of space, and the "perceived" of space, to screen, select, and define the main subjects of this research: gender, psychological, social and cultural four heterogeneous spaces and their respective rationale. Introducing the theoretical framework of this topic, Foucault's heterotopias theory focused on the cultural construction, social relevance, structural heterogeneity, spatial and temporal synchronization/ synchronicity, internal exclusivity and spatial transcendence of heterogeneous spaces. These features are the specific representations in the four literary spaces of gender, psychology, society and culture in "Rabbit Tetralogy".

In the first part, "Confrontation and Compromise: the Gender Heterogeneity Space in Rabbit Tetralogy, the author believes that people, the social beings, always live in a certain society, and characters of different genders form their own gender space in social communication.

This dissertation probes into the development and expansion of the female space in light of the sexual liberation movement in America in the 1960s in Rabbit Redux, and the adhering to and decay of Harry, the Rabbit to the patriarchal tradition in Rabbit, Run and Rabbit at Rest. The superposition, collocation and conflict between the gender spaces, as well as the masculinity crisis of Harry, the Rabbit, are vividly revealed in Rabbit Tetralogy.

In the second part, "Desire and Impulse: the Psychological Heterogeneous Space in Rabbit Tetralogy, the author points out that the psychological space refers to the complexity of the multiple contradictions between individuals and society caused by the different living environments of individual characters and their different psychological needs and desires. Freud and Lacan's psychoanalytic theories shed light on this dissertation to study the awakening and germination of female (such as Janice) self-consciousness caused by/due to spatial displacement and the repression/suppression and fragmentation of male self-consciousness such as Rabbit caused by spatial juxtaposition through the analysis of Rabbit Redux and Rabbit is Rich. Focusing on the analysis of multiple psychological conflicts, such as ego and id, ego and other, ego and society, this dissertation reveals the collision and squeeze of psychological space resulting from the transformation of social identity, and realizes the transformation from "external space " to "internal space" of novel characters.

In the third part, "Contradictions and Conflicts: the Social Heterogeneous Space in Rabbit Tetralogy, the author emphasizes that the social space in this chapter includes family space, work space and American social space. The family is the epitome of society. This chapter first focuses on the fragmentation and reorganization of the Rabbit family space. The differences in family background, educational background, ability and personality have led to/contributed to the heterogeneity of the family space 
constructed/built by the marriage between Rabbit and Janice, which is one of the reasons for Rabbit's strong dissatisfaction with life. The disappointment, fear, suffering/tribulation and misfortune of the protagonist, Rabbit, from a lower-class family in the American society, is a microcosm of the entire American society. Foucault pointed out that in a society of the same people or different nationalities, each relatively constant social stage or cultural form in different times is a heterogeneous space. The Rabbit family and the later temporary "new family" are the specific micro-social heterogeneous spaces. The American society from the late 1950 s to the early 1990 s is the social heterogeneous space in the macro sense, the conservatism in the $1950 \mathrm{~s}$, the turbulence in the 1960s, the mediocrity in the 1970s and the demise of values in the 1980s. With the Great Depression, the Vietnam War, the Black People's Rights Movement, sexual liberation, hippies, energy crisis, and drug abuse, etc., contemporary American society is full of/beset with noise/sorrow and turmoil. Through Rabbit Redux, Rabbit is rich, Rabbit at Rest, from the fragmentation and reorganization of the Rabbit family space to the solidification and flow of the Rabbit work space, it finally targeted at the ambiguity and turmoil of American social space, pointing out that the United States is a violent space with fierce conflicts of various forces, which is different from the ordinary, different from the common sense, different from the normal state, revealing the research significance of the space problem rising to the "social" level.

In the fourth part, "Void and Disillusionment: the Cultural Heterogeneous Space in Rabbit Tetralogy, the author reveals that the culture in this chapter refers to social behavior and norms in human society. Intangible culture such as social organization principles, mythology, philosophy, literature, etc. is opposed to material culture, such as technology, architecture and art. This chapter, through the observation of novels such as "Rabbit Redux", elaborates on the heterogeneity caused by the innate contradiction of American Dream and Counter-Cultural movement (including sexual liberation movements, black people's rights movements, ethnic conflicts, etc.) as cultural spaces, and the inevitability of its final destruction/disintegration. The beliefs and lack of religious feelings, the anxiety and loss of the "counter-cultural" movement, the pursuit and confusion of the "American Dream", as well as their inherent contradictions and the inevitability of their eventual collapse reveal the "cultural contradictions " in contemporary American society caused by the evolution/transformation of values. The prevalence of hedonism in American society has deeply affected the emerging middle class, who hover between religious beliefs and desires. / who are unable to extricate themselves from religious beliefs and desires. The Puritan tradition, once the spiritual pillar of the American people, is now in a precarious situation. The contradiction and conflict between the belief crisis and the pursuit of self in the
American culture are in full swing under the contemporary conditions and becoming increasingly fiercer.

In the concluding part, on the macroscopic level, future study focuses on the spatial connotation in "Rabbit Tetralogy", the three major issues, namely, "why he wrote space", "what space he wrote", and "how he wrote space". In "Rabbit Tetralogy", "space" is not only the place of the historical transformation of modern American society, but an important representation of the social changes. It is also a visible social result of modern American society, which is the result of the current American social space change. On the micro level, this dissertation clarifies the literary space types in Updike's Rabbit Tetralogy, which are classified into four categories, i.e., gender space, psychological space, social space and cultural space. These literary spaces are not only the production of physical space such as geographical landscape, but also the psychological impression of the character space of the novel and spatial sense of different genders of men and women, as well as the reproduction of American social and cultural space.

In Updike's "Rabbit Tetralogy", Harry, the Rabbit's personal misfortune and family breakdown are the epitome of American society as a whole. This future study, with different historical events as the background, vividly depicts the loss of religious belief in American society in post-industrial era, the decay of the traditional culture and value, and the innate contradiction of new culture and value, via the description of heterogeneity of the gender space, psychological space, social space and cultural space.

\section{Conclusions}

Updike's masterpiece, using skillful realism, succeeded in drawing a panoramic picture of the American society from the 1950s to the early 1990s in the "Rabbit Tetralogy." Updike strives to reflect the changes in contemporary American social culture for nearly half a century from the "rabbit" Harry, the everyman of the American society and the life experiences of his ordinary family. "Rabbit Tetralogy" truly reflects the living conditions of the contradictions of contemporary Americans: endless pursuit of free life or independent self and the embarrassment and helplessness of it; the customary life and hedonism under the traditional values and the intense collision of self-indulgent lifestyles inspired by thought. The endless pursuit of so-called freedom and self is bred.

In "Rabbit Tetralogy", Updike constructed a literary space with various characteristics and different natures. There are physical spaces such as work space and family space, as well as literary spaces on the spiritual level such as gender space, psychological space, social space and cultural space. It is inseparable from the original intention and reason of Updike's depiction of literary space in his works. 


\section{REFERENCES}

[1] DONG Wensheng, Rabbit: Modern Sisyphus - On the Image of Rabbits and the Structure of Fiction in Rabbit, Run. Foreign Literary Review No.4 1996

[2] DONG Wensheng, Round and the Net: Dream and Dilemma - "Rabbit, Run" Theme and Image. Foreign Literature No.3 1998

[3] Foucault, Space, Knowledge, Power, edited by BAO Yaming: Postmodernism and Geography Politics, Shanghai: Shanghai Education Press, 2001

[4] GUO Jide, Testimony of the Upheaval in American Society: John Updike and His Rabbit Tetralogy. Foreign Literary Research, No. 6 p.148, 1992

[5] GUO Yingjian, The Religious Consciousness in the View of John Updike's Literature Foreign Literature No. 6 pp.19-20, 2000

[6] GUO Yingjian, Study of John Updike in China. Foreign Literature No.4, 2005

[7] GUO Yingjian, Aversion or Sympathy: Rereading Updike's Feninine Novels Anglo-American Literature No. 29 pp.173-184, 2018

[8] HAO Yunzhi, The Materialized World of America's Middle-Class Journal of Tianjin International Studies University No. 5 pp.61-64, 2011

[9] HAO Yunzh, John Updike and Christianity. Dissertation of Nankai University. 2007

[10] HONG Zengliu, On the Secularized Religion Theme in Rabbit, Run. Contemporary Foreign Literature No.4. pp.111-116, 2004

[11] JIN Hengshan, Why Rabbits to Run? "Rabbit, Run" cultural interpretation. European and American literary series first series Beijing: People's Literature Publishing House, 2002.

[12] JIN Hengshan, What Made the Rabbit Come Back? Updike's Self Identity Crisis in "Rabbit Redux" and Social and Cultural Contradictions in the 1960s. Foreign Literature, No.6 pp. 68-76, 2005

[13] JIN Hengshan, Updike and Contemporary American Society - Updike's Study of Ten Novels. Beijing: Peking University Press, 2008.

[14] LUO Chang-Bin, QIAN Man-Su: The Life of Rabbits and Their Implications - On Updike's Rabbit's Tetralogy .Journal of Sichuan International Studies University, 1997

[15] QIAN Mansu, The Transformation of Society, The Confusion of Life - John Updike and Rabbit Trilogy World Literature No. 5 pp.239-243, 1986

[16] SHENG Ning, Surfers: Updike briefly. Foreign Literature Studies No.2 1984

[17] ZHU Gang "American Literary Theory in the Twentieth Century", Beijing: Peking University Press, 1994.
[18] WANG Yuexi: A Political Novel Perspective, On the Political Tendency of John Updike's Rabbit Tetralogy Contemporary Foreign Literature No.4 p.84, 1998

[19] WANG Shouren: Puzzled by a Loser: On Updike's "Rabbit at Rest" Foreign Literary Review No.3 p.88, 1993.

[20] WEN Chu-an, Updike's New Exploration of Female Consciousness. Foreign Literary Review No.1 1988

[21] UPDIKE John, Rabbit at Rest. New York : Ballantine Books, 1990

[22] UPDIKE John, Rabbit Is Rich. New York : A Fawcett Crest Book, 1982

[23] UPDIKE John, "Rabbit Remembered" in Licks of Love: Short Stories and a Sequel New York: The Bllantine Publishing Group, 2000

[24] UPDIKE John, Rabbit Redux. New York: A Fawcett Crest Book, 1972

[25] XU Ming, On the Innovation of American Social Fashion Novels and Rabbit Tetralogy Foreign Literature Studies No.6 pp.152-158, 2012

[26] ZHAO Cheng, Review on Home and Abroad Study of John Updike's Rabbit Tetralogy Masterpiece Review No.1 pp.66-68, 2015

${ }^{1}$ This article is a phased achievement of Foreign Language Project of the Top Quality Applied Research in Social Sciences of Jiangsu Province On the Inheritance and Surpass of John Updike's Novels over the Realism Tradition of English Literature (Project No: 17JSYW-15) 